\title{
DOES INPUT SECTOR LIBERALIZATION PROMOTE QUALITY INNOVATION AND EXPORTS?
}

\author{
By \\ Swapnendu Bandyopadhyay* \\ CSDILE/ School of International Studies \\ Jawaharlal Nehru University \\ New Delhi - 110067, India. \\ Rajat Acharyya $^{++}$ \\ Department of Economics, Jadavpur University, \\ Calcutta- 700032, India
}

March, 2004.

\footnotetext{
-We are extremely grateful to two anonymous referees of this journal whose incisive and thoughtful suggestions led to substantial improvement in the quality of the paper. We also thank Partha Sen, Abhirup Sarkar, Tarun Kabiraj and seminar participants at Delhi School of Economics for their comments suggestions on an earlier draft. The usual disclaimer applies, however.

* Corresponding Author: Department of Economics, Jadavpur University, Calcutta - 700032, West Bengal, India. Email- swapnendu@hotmail.com.

++ Email: racharya@cal2.vsnl.net.in
} 


\begin{abstract}
This paper examines the relationship between input sector liberalization and product quality innovation and export orientation by a LDC firm given the complementarity between high input quality and high product quality. We show that input sector liberalization per se may not induce quality innovation and outward orientation. In fact in some situations ceteris paribus input sector liberalization may increase the odds in favour of low quality production. We show that total output sector liberalization, or surprisingly, a suitable degree of output sector protection then is needed to be combined with input sector liberalization so that quality innovation is induced.
\end{abstract}

\title{
JEL Classification: L1, D43.
}

Key Words: Input sector liberalization, Product quality innovation, export orientation. 


\section{INTRODUCTION:}

This paper examines the impact of input-trade liberalization on innovation of high-quality final good by a producer in a typical developing country. Poor quality of products in the developing countries often adversely affects their export growths particularly in the advanced industrialized countries. Mostly such poor quality can be attributed to inferior technology of the domestic firms. Immediately the question that crops up is why these firms lack the incentive for quality innovation. The major argument of course is that high tariff on the import of final good raises the profitability of the domestic market relative to the world market in such a way that it lowers the incentive for outward orientation and therefore for quality innovation [Acharyya (1995), Desai (1980), Lall (1984)].

A closely related argument which more often appear in the informal discussions on liberal trade policies as a development strategy is that high tariff on better quality foreign input induces the domestic producers to use poor quality indigenous inputs, which in turn causes the quality of the final good fall well below the international standards. But though there is some evidence on the differences in quality of inputs that are available domestically and abroad, it is not clear whether input trade liberalization per se provides sufficient impetus for innovation of the high-quality product. For example, Premachandra and Rajapatirana (1998), in their study of the Sri Lankan liberalization experience point out that "liberalization of imports increased access to better quality and cheaper intermediate inputs, reducing the reliance on state owned enterprises, which had provided high-cost, low-quality inputs before the liberalization". On the other hand, a study commissioned by the Ministry of Commerce and Industry India, executed by ICRA Advisory Services and Frost and Sullivan, show that poor quality output of the Indian Textile industry is caused to a 
large extent by low-quality domestic inputs (Business Line, Internet Edition, August 17, 2002).

But these piecemeal studies do not suggest that availability of high-quality foreign input through trade liberalization would necessarily help enhancing quality of final products in these cases. The primary reason for such doubts, which in fact motivates the present paper, is the lack of technical know-how required to combine the essential high-quality sophisticated foreign input with other local factors for producing the high-quality variety of the final good. This is best exemplified by the Indian experience. The design and production of telecom switches in India by C-Dot require import of the Application Specific Integrated Circuits (ASICS) from Motorola. But for better performance and functioning of these switches application specific software had to be developed ${ }^{1}$. This raises the following issue: Does input-trade liberalization always induce the domestic producers to innovate the required technology for producing the high-quality final good by using the foreign input? If there are instances where it has influenced the decision for innovation and enhancement of quality of the final good, can those be regarded as a general phenomenon?

But whatever little evidence can be gathered on the link between input-trade liberalization and R\&D efforts, does not help us help us answer these questions in a very conclusive way. From mid 1980s many developing countries had started lowering the average tariff rates and liberalized their trade policies. During 1991-1996 Bangladesh lowered its average tariff from $88.6 \%$ to $27.4 \%$, India from $79.2 \%$ to $38.7 \%$, Malaysia from $16.9 \%$ to $8.7 \%$ and Thailand from $37.8 \%$ to $20 \%$. But the R\&D expenditure as a percentage of GDP for some of them (such as Bangladesh, Korea and Mexico) has increased only marginally (see Table-1) whereas those in Chile,

\footnotetext{
${ }^{1}$ Even import of foreign technology in power sector in India required training of local labour force by foreign technicians and skilled personnel.
} 
Malaysia and Thailand show declining trends. On the other hand, it is evident from Table-2 that the share of high technology exports in manufacturing exports, which is a first hand indicator of share of high-quality exports in the export basket, has increased only for countries like India, China, Malaysia and Korea whereas it has predominantly decreased for Bangladesh, Pakistan, Uganda. Majority of the countries show a fluctuating trend in high technology exports.

The existing theoretical literature also has almost nothing to offer. While there has been quite a few theoretical works that examine the effect of output sector protection (or liberalization) on the quality choice of firms, surprisingly there is hardly any such theoretical formulation that sets out how input protection might affect the quality innovation decision of firms ${ }^{2}$.

This paper attempts to bridge this theoretical gap. More precisely, we address following two sets of issues. First, does reduction of input tariff always raise the incentive for quality innovation? Second, when such input sector liberalization by itself does not induce quality innovation, do we need to combine it with output sector liberalization?

Using a simple micro-theoretic framework, first of all, we show that input sector liberalization per se may not induce quality innovation. In fact in some situations ceteris paribus input sector liberalization may increase the odds in favour of low quality production. More precisely, when there is a non-prohibitive tariff on final imports, full liberalization of input sector does not necessarily lead to quality innovation. Either total output sector liberalization, or a suitable degree of output

\footnotetext{
${ }^{2}$ The theoretical literature on the impact of liberalization of trade in final good on product quality include notable contributions by Clemenz (1991), Herguera and Lutz (1998), Herguera, Kujal and Petrakis (2002) and Vandenbussche and Wauthy (2001). There is also a closely related literature on technology diffusion from North to the South [Coe and Helpman (1995), by Keller (1998) and Young (1991)]. For an excellent survey see Keller (2001). Also empirical studies by Aw and Roberts(1986) and Feenstra (1998) examine trade policy effects on quality choices by firms.
} 
sector protection is needed to be combined with input sector liberalization to induce the domestic firm to invest in a quality-improving R\&D. But, with a prohibitive tariff on final imports, even partial input sector liberalization may be 'sufficient' for quality innovation for some low R\&D expenditures.

Input sector liberalization does not just mean lowering of tariffs on inputs. Many physical restrictions on imports are also in place in the developing countries. To examine how far relaxations of such restrictions can induce quality innovation, we recast our analysis in an initial situation where there is a ratio-quota in place. That is the final good firm is required to purchase a certain proportion of its input requirement from the local suppliers and the ad-valorem tariff on low-quality final import that is granted is conditional upon meeting this requirement. This regime is essentially the content protection scheme discussed by Corden (1971). Under these circumstances we check the sufficiency of output sector liberalization vis-à-vis input sector liberalization in inducing product-quality innovation. Under such circumstances the output sector liberalization per se induces product-quality innovation whereas uniform input sector liberalization per se may not, once again, induce product-quality innovation. Although one may point out that this content requirement violates WTO norms, we find this analysis useful because it conveys the crux of the matter well.

All these results have some obvious implications for sequencing of input sector and output sector liberalization in the context of liberalization policy as an instrument of innovation.

The rest of the paper is organized as follows. In section- 2 we describe the structure of the model and the tariff regimes. In section-3 we examine the innovation decision (quality innovation) of the final-good firm under trade liberalization. Section 
3.1 considers input sector liberalization and Section 3.2 discusses implications of output sector liberalization. In section-.3.3 we consider physical restrictions on import of foreign input and re-examine the above mentioned issues. Finally section-4 concludes the paper.

\section{THE MODEL:}

Given the perspective as spelled out above, consider a market for a final good $\mathrm{X}$ in a developing country, where a single domestic producer operates ${ }^{3}$. Given the world technology, the final good can be of two types: low-quality $(\mathrm{L})$ and high-quality $(\mathrm{H})$. These are the two varieties that are available in the world market. But whereas the domestic firm can produce the low-quality good at constant marginal cost (henceforth MC) and zero fixed cost, it cannot produce the high-quality variety. An essential input (I) for producing the final good $\mathrm{X}$ that is available in the perfectly competitive domestic input sector is of very poor quality compared to the variety that is available in the competitive world market for the input. Moreover, even if the domestic firm is allowed by the local government to import the high-quality foreign input at duty-free world price, it simply does not have the technical know-how to combine such foreign input with other local factors of production to produce the high-quality variety. The domestic firm thus must invest in an $R \& D$ to develop the technology to use the foreign input to produce the high-quality variety ${ }^{4}$. Thus, whereas the low-quality domestic input cannot be used to produce the high-quality final good, the high-quality input imported from abroad, though essential, but does not per se improve the quality

\footnotetext{
${ }^{3}$ The results derive below do not change qualitatively if there are more domestic firms who compete in Cournot fashion. Assumption of a single domestic firm is just a simplification.

${ }^{4}$ As pointed out by an anonymous referee, if we allow foreign investment, the high-quality final good can be produced by the subsidiary unit without further investment in R\&D as it can access to the same technology as used by the parent firm. However, to focus on how input-tariff reduction improves product-quality innovation we abstract from this issue.
} 
of the final good. These assumptions, though may seem restrictive, capture the actual technological situations prevailing in the developing countries as mentioned earlier ${ }^{5}$.

The difference in the quality of domestic and foreign input has another implication in this paper: difference in their productivity in producing the low-quality variety of the final good. Whereas the low-quality indigenous input has a low marginal product i.e. a high input-output ratio $\bar{\gamma}$, the high-quality foreign input has a high marginal product and thus a low input-output ratio $\gamma$. This means, if the domestic final-good producing firm does not innovate, then the only benefit from using the foreign input is a reduction of the $\mathrm{MC}$ of output of the low-quality variety. Moreover, for analytical convenience we assume that once the required technology to produce high-quality input is developed through $\mathrm{R} \& \mathrm{D}$, amount of the foreign input (per unit output) needed to produce the high-quality variety of the final good is the same as is needed to produce the low-quality output.

Let the constant $\mathrm{MC}$ of producing the low-quality domestic input be $\mathrm{c}_{\mathrm{I}}$ and the high-quality foreign input be $\mathrm{c}_{\mathrm{I}} *$ and for simplicity we assume $\mathrm{c}_{\mathrm{I}}=\mathrm{c}_{\mathrm{I}} *$ implying that the domestic input price $\mathrm{P}_{\mathrm{I}}=\mathrm{c}_{\mathrm{I}}=\mathrm{c}_{\mathrm{I}}{ }^{6}$. The high-quality foreign input market is assumed to be perfectly competitive so that $\mathrm{P}_{\mathrm{I}}{ }^{*}=\mathrm{c}_{\mathrm{I}}{ }^{*}$. This coupled with the previous assumption imply that $\mathrm{P}_{\mathrm{I}}=\mathrm{c}_{\mathrm{I}}=\mathrm{c}_{\mathrm{I}}^{*}=\mathrm{P}_{\mathrm{I}}{ }^{*}$. Indeed this assumption is made for simplicity. All we need is that the MC of output while using the foreign input should be less than the MC of output when domestic input is used. Thus the marginal cost of output for the final-good firm using the home input is $\mathrm{c}_{\mathrm{I}} \bar{\gamma}$ and the foreign input is $\underline{\mathrm{c}}=$

\footnotetext{
${ }^{5}$ This of course raises the issue why such differences persist at all? That is, what prevents the domestic input producers to invest in input-quality improving R\&D. Part of the reason once again is the high protection offered to the domestic input sectors by the governments in the developing countries.

${ }^{6}$ Although the production of foreign high quality input should have a higher MC i.e. $\mathrm{c}_{\mathrm{I}}{ }^{*}>\mathrm{c}_{\mathrm{I}}$, we can assume that the foreign input producers have a better technology and thus can produce inputs at a lower MC such that $\mathrm{c}_{\mathrm{I}}{ }^{*}=\mathrm{c}_{\mathrm{I}}$.
} 
$\mathrm{P}_{\mathrm{I}}^{*} \gamma=\mathrm{c}_{\mathrm{I}} \gamma$. With the home country government imposing an input tariff $\mathrm{t}_{\mathrm{I}}$ on the foreign input, the tariff inclusive input price becomes

$$
\left(1+t_{I}\right) P_{I}^{*}=\left(1+t_{I}\right) c_{I}
$$

Consequently, $\mathrm{MC}$ of output for the final-good firm equals $\bar{c}=\left(1+\mathrm{t}_{\mathrm{I}}\right) \mathrm{P}_{\mathrm{I}}^{*} \gamma=\left(1+\mathrm{t}_{\mathrm{I}}\right)$

$\mathrm{c}_{\mathrm{I}} \gamma$.

That is the break-even input tariff should be such that

$$
\left(1+\mathrm{t}_{\mathrm{I}}\right) \mathrm{c}_{\mathrm{I}} \gamma=\mathrm{c}_{\mathrm{I}} \bar{\gamma}
$$

In other words the domestic input firms break-even for,

$$
\mathrm{t}_{\mathrm{I}}=t_{I}{ }^{0}=\frac{\bar{\gamma}-\gamma}{\gamma} .
$$

Thus only for $\mathrm{t}_{\mathrm{I}} \geq t_{I}^{0}$ the domestic input industry makes non-negative profit and operates. We assume that the initial input tariff is set at $\hat{t}_{I}=t_{I}^{0}$. Let $\hat{c}$ be the corresponding $\mathrm{MC}$ of producing the low-quality good

$$
\text { i.e. } \quad \hat{c}=\left(1+\hat{t}_{I}\right) \mathrm{c}_{\mathrm{I}} \gamma \quad \forall \quad \hat{t}_{I} \leq t_{I}^{0}
$$

When $\hat{t}_{I}=t_{I}^{0} \hat{c}=\mathrm{c}_{I} \bar{\gamma}$. Interestingly below $t_{I}^{0}$ the output firm will start to import the high-quality input from abroad as the constant MC of output is lower in that case and the domestic input firms will shut down.

Let us now turn to the final-good sector. We assume that there is no tariff on the high quality good, i.e. the high quality good sector is completely open to foreign competition. The implication of this assumption is that after successful quality innovation the domestic firm has the incentive to sell the high quality product in the domestic market as well as in the world market (export market) that in other words is the integrated world market. The pre-innovative integrated world market (henceforth 
world market) for the high quality good is characterized in the following way. For simplicity we assume that there are two firms ${ }^{7}$ in the world market selling the high quality product competing in quantities. The assumption of quantity competition is made to ensure a positive rent from producing the high quality product (in the world market). Otherwise there will be no incentive for quality up-gradation and the entire analysis becomes trivial and uninteresting. One important comment is warranted at this point. We assume that after successful quality innovation the domestic firm will switch over totally to high quality production. (It may also operate as a multi-product firm producing both low and high quality good in the domestic market but that will not change the analysis much). After successful quality innovation (if the domestic firm decides to undertake it at all), it will compete with these foreign firms in the world market and there will be a three firm cournot oligopoly in the world market. Again for the sake of simplicity we assume that firms are symmetric. On the other hand, import of the low-quality final good is subject to a non-prohibitive ad-valorem tariff t. With world market for low quality good perfectly competitive this means,

$$
P_{L}=(1+t) P_{L}^{*}=(1+t) c_{I} \gamma
$$

Protection granted only to the low-quality production is not at odds with reality. In India, for example, quantitative restrictions on almost all import items have been dismantled. Tariff rates have also been slashed from April 2001. But quality regulations are imposed by which goods of lower qualities are not allowed to be imported. Imports of automobiles from Japan in Bangladesh face similar quality regulations by which refurbished cars that are more than five years old are prohibited to be imported. There are other examples as well. European Union applies higher tariff on the imports of low-quality wheat to high-quality wheat. Also very recently

\footnotetext{
${ }^{7}$ The model goes through with any finite number of firms.
} 
Poland waived duty on imports of high-quality furniture and coarse wool whereas duty on low-quality imports is still in place. We capture these restrictions in terms of tariff on imports of low-quality goods.

Suppose the domestic demand function for the low-quality good is linear:

$$
\mathrm{P}_{\mathrm{L}}=\mathrm{a}-\mathrm{X}_{\mathrm{L}}
$$

and the integrated world demand for the high-quality good is:

$$
\mathrm{P}_{\mathrm{H}}=a^{\prime}-\mathrm{X}_{\mathrm{H}}
$$

We assume that $a^{\prime}>4 a$ implying that the integrated world market for high-quality good is sufficiently greater than the domestic market for the low quality good. The reason for this assumption will be made clear later.

Given the ad-valorem tariff on the low-quality foreign good, the domestic monopolist can charge a price equal to $(1+\mathrm{t}) \mathrm{P}_{\mathrm{L}} *$ but no more than that in the domestic market. If such a price covers its $\mathrm{MC}$ of producing the low quality good by using the indigenous input, $\hat{c}$ as defined in (2), the firm will produce and given constant $\mathrm{MC}$, will supply the entire demand at that price.

That is for any given $t$, output produced by the home monopolist is,

$$
\mathrm{X}_{\mathrm{L}}=\mathrm{a}-(1+\mathrm{t}) \mathrm{c}_{\mathrm{I}} \gamma
$$

and the corresponding profit is

$$
\begin{aligned}
\pi(\hat{c}, \mathrm{t}) & =\left[(1+\mathrm{t}) \mathrm{P}_{\mathrm{L}}^{*}-\hat{c}\right]\left[\mathrm{a}-(1+\mathrm{t}) \mathrm{P}_{\mathrm{L}}^{*}\right] . \\
& =c_{I} \gamma\left(\mathrm{t}-\hat{t}_{I}\right)\left\{\mathrm{a}-(1+\mathrm{t}) c_{I} \gamma\right\}
\end{aligned}
$$

From (9) we obtain restriction on the tariff on low-quality product that induces the domestic firm to produce as:

$$
\mathrm{t} \geq \hat{t}_{I}
$$


This endogeneity of the final-good tariff, i.e. the link between extent of protections offered to the final-good and the input producing domestic firms, is quite obvious to those familiar with the literature on effective rate of protection and content protection scheme [ Corden (1971) ].

In particular, the government intending to protect the low-quality final-good producing firm(s) must take into account the input protection that it has granted and while setting the tariff on final good it must satisfy (9). More generally, $t$ should be set as,

$$
\mathrm{t}=\mathrm{f}\left(\hat{t}_{I}\right) \text { where } f^{\prime}\left(\hat{t}_{I}\right)>0 \text {. }
$$

It is straightforward to check that $\pi(\hat{c}, \mathrm{t})$ will be a positively sloped concave function reaching a maximum at the prohibitive tariff $\bar{t}=\frac{a+\hat{t}_{I} \gamma_{-} c_{I}-c_{I} \gamma_{-}}{2 c_{I} \gamma_{-}}$and becomes horizontal thereafter. That is for $\mathrm{t}>\bar{t}$ the firm can earn a monopoly profit

$$
\pi_{\mathrm{m}}(\hat{c})=(\mathrm{a}-\hat{c} / 2)^{2}=\frac{\left[a-\left(1+\hat{t}_{I}\right) c_{I} \gamma_{-}\right]^{2}}{4}
$$

by charging the monopoly price $\mathrm{P}_{\mathrm{m}}(\hat{c})=\frac{a+\left(1+\hat{t}_{I}\right) c_{I} \gamma}{2}$. Accordingly, domestic price, output and profit will remain invariant with respect to change in the tariff rate beyond $\bar{t}$. Interestingly enough $\frac{\partial \bar{t}}{\partial \hat{t}_{I}}>0$, implying that as the fixed input tariff is increased the prohibitive output tariff must also increase. This is quite intuitive as the monopoly price that corresponds to prohibitive tariff varies positively with the MC, $\hat{c}$, and by (4) that depends on the input-tariff. But before we proceed further note that 
if the local government had set the tariff on the low-quality final good imports to maximize national welfare, then it would choose the same rate as the input tariff rate:

Lemma1: Given any input tariff $\hat{t}_{I}$, the welfare maximizing low quality output tariff is equal to the input tariff. That is $t^{*}=\hat{t}_{I}$.

Proof: The total domestic welfare from low quality production is the sum of total consumer surplus from low quality consumption and the domestic monopolists profit.

The total consumer surplus is defined as $\mathrm{CS}=\int_{(1+t) c_{I} \gamma}^{a}(a-p) d p$ and the total producers surplus is given in equation (9). Maximizing $\mathrm{W}=\mathrm{CS}+\pi(\hat{c}, \mathrm{t})$ with respect to ' $\mathrm{t}$ ' and after simplification we get $t^{*}=\hat{t}_{I}$ and $\frac{\partial^{2} W}{\partial t^{2}}<0$. This completes the proof.

Note that at this optimum tariff on low quality imports, profit of the domestic output firm falls to zero. This essentially reflects the conflict between welfare-maximizing and protective targets of tariff setting in this model. Thus in this set up if the government intends to protect the domestic industry, it should set a sub-optimal output tariff above the optimum tariff $\hat{t}_{I}$. Since, here our purpose is to examine the link between protection and quality innovation we assume that government choose the tariff rate from the set $\left(\hat{t}_{I}, \bar{t}\right)$.

Let us now turn to the firm's decision to innovate and produce the high-quality good given the above mentioned tariff regimes.

\section{QUALITY INNOVATION:}

In this section we examine the decision to produce the high-quality good starting with the ad-valorem input tariff, $\hat{t}_{I}=t_{I}^{0}$, the ad-valorem tariff on the low- 
quality good, $t \in\left(\hat{t}_{I}, \bar{t}\right]$ and no tariff on the high-quality good. Our aim here is to derive the relation between input sector liberalization and product quality innovation. Given the non-prohibitive input tariff, $t_{I}^{0}$, the output firm can purchase the highquality input necessary for product-quality innovation from abroad at a price $\left(1+t_{I}^{0}\right) c_{I}$. But this is not sufficient. It must develop the technology to produce the high-quality good as well through $R \& D$ which involves a fixed cost, $F_{q}$. Suppose innovation outcome is certain. Of course this is only a simplifying assumption. Then after product quality up-gradation the domestic firm will sell the high quality product in the integrated world market. As mentioned previously the domestic final-good firm can earn a three firm symmetric Cournot oligopoly profit

$\pi(Q)=\frac{\left\{a^{\prime}-\left(1+t_{I}^{0}\right) c_{I} \gamma\right\}_{-}^{2}}{16}=\frac{\left(a^{\prime}-c_{I} \bar{\gamma}\right)^{2}}{16}$

in the world market if it decides to innovate ${ }^{8}$. However, it does so only if,

$$
\pi(Q)-F_{q} \geq \pi(\hat{c}, t)
$$

The RHS is the profit that the final-good firm earns from selling the low-quality good in the domestic market, whereas LHS is the net profit from selling the high-quality good in the world market. That is, quality innovation must be relatively profitable. The tie-breaking rule applied here is that for strict equality, the output firm prefers quality-innovation.

Before proceeding further we want to state the following lemma and derive some of the important threshold values for the quality innovation cost $F_{q}$.

\footnotetext{
${ }^{8}$ Note that the input tariff inclusive $\mathrm{MC}$ of output is $c_{I} \bar{\gamma}$ since high-quality production requires the high quality input, that could only be purchased by paying the tariff inclusive price. (See equation (1)). Thus the profit function of the domestic firm for high-quality product depends on $\bar{\gamma}$.
} 
Lemma 2: The output firm innovates product quality for any tariff on low-quality final imports, prohibitive or non-prohibitive, iff

$$
\begin{gathered}
F_{q} \leq \hat{F}_{q}=\frac{1}{16}\left[\left(a^{\prime}-2 a+c_{I} \bar{\gamma}\right)\left\{a^{\prime}+2 a-3 c_{I} \bar{\gamma}\right\}\right] \\
\text { or, in general } F_{q} \leq \hat{F}_{q}=\frac{1}{16}\left[\left\{a^{\prime}-2 a+(1+t) c_{I} \gamma_{-}\right\}\left\{a^{\prime}+2 a-3\left(1+\hat{t}_{I}\right) c_{I} \gamma\right\}\right] \forall \hat{t}_{I} \leq t_{I}^{0}
\end{gathered}
$$

Proof: The final-good firm would prefer producing the high-quality good irrespective of the level of $t$ when,

$$
\pi(Q)-F_{q} \geq \max \pi(\hat{c}, t)=\pi_{m}(\hat{c})
$$

Since $\pi_{\mathrm{m}}(\mathrm{Q})$ is invariant w.r.t. tariff on low quality final good $(\mathrm{t})$ and $\pi(\hat{c}, t)$ is monotonic upto $\bar{t}$ and remains constant thereafter. Using (12) and (13) this condition boils down to (15). Hence the claim.

What emerges from above is that for "small" R\&D costs in the sense defined in (15), quality innovation always takes place. Moreover, this is the case as long as input tariff is non-prohibitive, no matter how large or small it may be. Also when $t_{I}=0$ we get an upper limit of $F_{q}$ such that $\left.F_{q} *=\frac{\left(a^{\prime}-c_{I} \gamma\right.}{16}\right)_{-}^{2}$ for which quality innovation is viable. Combining the two we get a range of $F_{q}$ for which we can explore some nontrivial results.

\subsection{INPUT-SECTOR LIBERALIZATION:}

To examine the effect of input sector liberalization let us first consider the relationship between innovation decision and input-tariff, given the ad-valorem tariff 
on low-quality final import. Let us begin with non-prohibitive output tariff $t_{0}$ on final imports and input tariff at $t_{I}^{0}$. Suppose for some $F_{q}^{0} \in\left[\hat{F}_{q}, F_{q} *\right]$, the initial tariff regimes were just conducive for product-quality innovation. Recalling the innovation decision from (14), the following must therefore be true:

$$
\left[\left(1+t_{0}\right) c_{I} \gamma_{-}-c_{I} \bar{\gamma}\right]\left[a-\left(1+t_{0}\right) c_{I} \gamma\right]=\frac{\left[a^{\prime}-c_{I} \bar{\gamma}\right]^{2}}{16}-F_{q}{ }^{0}
$$

where $t_{0}$ denotes the initial tariff on low-quality final imports. Such an initial position is indicated by point B in Fig-1.

\section{FIGURE-1 GOES HERE}

When $\hat{t}_{I}$ is reduced keeping $\mathrm{t}_{0}$ fixed, the profits from low-quality and high-quality production increase at the following rates:

$$
\begin{aligned}
& \frac{\partial \pi\left(\hat{c}_{,} t_{I}\right)}{\partial \hat{t}_{I}}=-\left[a-\left(1+t_{0}\right) c_{I} \gamma_{-}\right] c_{I} \gamma_{-} . \\
& \frac{\partial \prod(Q)}{\partial \hat{t}_{I}}=-\frac{\left[a^{\prime}-\left(1+\hat{t}_{I}\right) c_{I} \gamma_{-}\right] c_{I} \gamma_{-}}{8} . \\
& \frac{\partial^{2} \Pi(Q)}{\partial \hat{t}_{I}^{2}}>0 .
\end{aligned}
$$

where $\Pi(Q)=\pi(Q)-F_{q}$ is the net profit from quality innovation. Thus, given $t_{I}^{0}$ and $t_{0}$, we were initially at point $\mathrm{B}$. When $t_{I}$ is reduced successively, the profit from sale of low-quality good increases at a constant rate as shown by the straight line, whereas the quality innovation profit increases at an increasing rate as indicated by the convex curve(s). Consequently, three possibilities emerge depending upon the parametric values. One is the case where $\Pi(Q)$ curve lies wholly below the $\pi(\hat{c}, t)$ curve for all $t_{I} \in\left[0, t_{I}^{0}\right)$. In such a case input sector liberalization cannot induce quality innovation. 
The other extreme case is the one where $\pi(\hat{c}, t)$ curve lies wholly below $\Pi(Q)$ curve implying input-sector liberalization, however small it may be, induces product-quality innovation. Finally, the intermediate case indicates a minimum dose of input-sector liberalization will induce product quality up-gradation. Of course, in these two cases, if $F_{q}>F_{q}{ }^{0}$ for sufficiently high $F_{q}$, input-sector liberalization by itself may not induce quality innovation similar to the first possibility.

We compare the intercepts of both $\Pi(Q)$ and $\pi(\hat{c}, t)$ curves when $t_{I}=0$ given $F_{q}{ }^{0}$ and $t_{0}$ as in equation (16). Given this $F_{q}{ }^{0}$, at $t_{I}=0$ we get

$$
\begin{aligned}
& \Pi(Q)-\pi\left(t_{0}, t_{I}=0\right) \\
= & {\left[\frac{\left(a^{\prime}-c_{I} \gamma\right)_{-}^{2}}{16}-\frac{\left(a^{\prime}-c_{I} \bar{\gamma}\right)^{2}}{16}\right]-\left[a-\left(1+t_{0}\right) c_{I} \gamma_{-}\right]\left[c_{I} \bar{\gamma}-c_{I} \gamma_{-}\right] . }
\end{aligned}
$$

From (18) what we get is that if the cost advantage while producing the high-quality good exceeds the cost advantage while producing the low-quality good due to a reduction in input tariff then product-quality innovation will take place at $t_{I}=0$ as is explained by the last two cases, otherwise product-quality innovation will not take place at $t_{I}=0$ as is shown by the $\Pi(Q)$ curve lying wholly below $\pi(\hat{c}, t)$ curve. The reason behind this kind of result is the higher productivity of high-quality input in both high-quality and low quality production. If high quality inputs are purchased duty free they can be used in the production of low quality goods thus reducing its unit cost of production. If this total cost advantage of using high quality input in low quality production exceeds the cost advantage while producing the high quality products, producers will start producing low-quality goods using high quality inputs. Therefore we get the following result: 
Proposition 1: Given the non-prohibitive tariff on final imports, input-sector liberalization per se may not induce product-quality innovation for $F_{q} \in\left[\hat{F}_{q}, F_{q} *\right]$.

Proof: Follows from the above discussion and Figure-1.

Another way of interpreting the above result is that when input tariff is reduced without tinkering the output sector, effective rate of output sector protection increases. So in essence input sector liberalization per se may serve as a protective device for the low-quality output sector. This again is mainly due to the cost effectiveness of the high-quality input in both low-quality and high-quality production.

Interestingly, suppose we take the case where product-quality innovation doesn't take place when input tariff is reduced. In this case if tariff on low quality imports (henceforth ' $t$ ') is reduced then the cost advantage from producing the lowquality good increases! That is if input sector liberalization is supplemented by a partial output sector liberalization quality innovation becomes relatively less profitable. The intuition behind this kind of a paradoxical finding is as follows: If ' $t$ ' is reduced, the domestic low-quality producer being a restricted monopolist in the domestic low-quality good market, will have to reduce its price (limit price) to deter foreign entry. This fall in price will lead to increased domestic demand in for the low quality good. Thus the total cost advantage of using the high-quality input in lowquality production gets magnified due to this expanded market coverage. This can also be seen from the relative slopes of both the curves, where the slope of $\Pi(Q)$ is independent of ' $\mathrm{t}$ ' [see eqn. (17b)], the absolute slope of $\pi(\hat{c}, t)$ increases with a reduction in ' $t$ ' [see eqn. (17a)]. Thus a reduction in ' $t$ ' makes product-quality innovation relatively unprofitable. So in this situation there are two ways to induce quality innovation. One is to open up the low-quality output sector totally i.e. setting 
$\mathrm{t}=0$ (this liberalization of the input sector and the output sector together is the bigbang approach) or increase protection in the low-quality good sector, i.e. raise 't' so that product-quality innovation is induced. Setting $t=0$ will integrate the domestic low-quality with the rest of the world. Given that the world market of the low quality good is perfectly competitive the domestic low quality producer's profit falls to zero. The domestic producer will then have no other choice but to innovate and upgrade its product quality. On the other hand increased protection on the low quality good will lead to a rise in price of that good in the domestic market leading to reduced market coverage. This leads to a fall in the total cost advantage of input sector liberalization on low quality production. Hence increased protection on the low quality good increases the odds in favour of quality up-gradation. Therefore we state the following result:

\section{Proposition 2:}

(a) Total input sector liberalization may have to be supplemented by total output sector liberalization or by a suitable degree of output sector protection to induce product-quality innovation.

(b) The first policy-combination leads to greater social welfare.

\section{Proof:}

(a) Follows from the above discussion and equations (17a), (17b) and 18.

(b) Follows directly from Lemma-1 and the fact that high quality production generates higher profit and higher consumer surplus.

This result can be used as a possible explanation of why some countries experienced increase in $R \& D$ expenditure and others did not during the process of globalization. It is interesting to note that input sector liberalization coupled with a suitable output 
sector protection gives a democratic government an additional policy tool to push forward the reform process with the desired outcome. Thus a democratic government facing problems in implementing a big-bang reform program may take this gradualistic route that too without much political fuss. Since we do not explicitly focus on this issue we leave the matter over here.

The previous analysis is carried out based on a particular value of $F_{q}$ such that the domestic producer is indifferent between quality innovation and no innovation (i.e. $F_{q}=F_{q}{ }^{0}$ ). But we must mention that the position of $\Pi(Q)$ depend on the value of $F_{q}$ implying that if we do not restrict $F_{q}$ then there can exist a possibility that for high and low input tariff ranges quality innovation is optimal and for the intermediate range low quality production is optimal given any non-prohibitive tariff $t$ $=t_{0}$ on low-quality imports ${ }^{9}$. This is illustrated in Figure- 2 .

\section{FIGURE-2 GOES HERE}

Depending on the values of the parameters we get three cases. $\Pi(Q)$ can lie wholly above $\pi(c, t)$. In this situation there is no input tariff for which low-quality production takes place. This is the trivial case where high-quality production takes place for all input tariff $t_{I} \in\left[0, t_{1}\right]$. But note that an output sector liberalization i.e. a reduction in 't' can play a spoilsport since $\pi(c, t)$ becomes steeper and we can end up having lowquality production dominating high-quality production for some input tariff ranges. $\Pi(Q)$ can intersect $\pi(c, t)$ only once. The third and most interesting situation is where $\pi(c, t)$ and $\Pi(Q)$ intersects twice. In this situation for sufficiently high input tariffs $t_{I} \in\left[\widetilde{\widetilde{t}}_{I}, t_{0}\right\rfloor$ and sufficiently low input tariffs $t_{I} \in\left[0, \widetilde{t}_{I}\right]$ high-quality production

\footnotetext{
${ }^{9}$ The mathematical calculations can be obtained from the authors on request.
} 
will take place and in the intermediate range low-quality production takes place. Thus high input sector protection or a high degree of input sector liberalization will induce quality innovation. The curvature properties of both the functions should be such that they intersect twice and this will obviously depend on the parameters of the model. Suppose $t_{I} \in\left[\widetilde{t}_{I}, \widetilde{\tau}_{I}\right]$. Within this tariff range high-quality production will not take place. Now a decrease in ' $\mathrm{t}$ ' will again increase the range of $t_{I}$ for which low-quality production holds. Again an increase in t will make high-quality production relatively profitable. Thus in this general structure also we can show that an input sector liberalization per se may not induce high-quality production. We may need to supplement it with a suitable degree of output sector protection.

What happens if there is prohibitive tariff on the low-quality final product? Under prohibitive tariff on low-quality final imports, "gross" relative profit from quality innovation is strictly positive:

$$
\left[\frac{a^{\prime}-\left(1+\hat{t}_{I}\right) c_{I} \gamma}{4}\right]_{-}^{2}-\left[\frac{a-\left(1+\hat{t}_{I}\right) c_{I} \gamma}{2}\right]_{-}^{2}>0
$$

given $a^{\prime}>4 a$. Thus, from lemma-2 we get is that quality innovation is relatively profitable for all $F_{q} \in\left\lfloor 0, \hat{F}_{q}\right\rfloor$ where, $\hat{F}_{q}$ is as defined in (15) irrespective of the degree of protection in the low-quality output sector, given a particular $\hat{t}_{I}$.

But once again, the non-trivial case is when $F_{q}>\hat{F}_{q}$. It is evident from (15) that $\hat{F}_{q}$ is a function of $\hat{t}_{I}$ with $\frac{\partial \hat{F}_{q}}{\partial \hat{t}_{I}}<0$ given $a^{\prime}>4 a$. This is shown in Figure-3. 


\section{FIGURE-3 GOES HERE}

This function gives different combinations of $F_{q}$ and $t_{I}$ for which quality innovation will just take place, i.e. the maximum tolerance limit of $F_{q}$ for different $t_{I}$ values, given prohibitive tariff on low-quality final imports. It is evident that for larger dose of input sector liberalization larger $F_{q}$ can be sustained. Does it mean that however large $\mathrm{F}_{\mathrm{q}}$ may be, there always exists an input tariff that is conducive to product quality innovation? Certainly not. In particular when $t_{I}=0, \hat{F}_{q}=\widetilde{F}_{q}$ where

$$
\widetilde{F}_{q}=\left[\frac{a^{\prime}-c_{I} \gamma}{4}\right]^{2}-\left[\frac{a-c_{I} \gamma}{2}\right]^{2}
$$

Also $\widetilde{F}_{q}-\hat{F}_{q}=\frac{1}{8} \hat{t}_{I} c_{I} \gamma\left[2 a_{-}^{\prime}-8 a+6 c_{I} \gamma_{-}+3 \hat{t}_{I} c_{I} \gamma_{-}\right]>0 \quad \forall \hat{t}_{I}>0$

This leads us to the following proposition:

\section{Proposition 3:}

Given prohibitive tariff on the low-quality output, there exists a suitable degree of input sector liberalization sufficient for product-quality innovation $\forall F_{q} \in\left\lfloor\hat{F}_{q}, \widetilde{F}_{q}\right\rfloor$.

Proof: Follows from the above discussion and Figure-3.

This indicates that for very high $\mathrm{R} \& \mathrm{D}$ costs, input sector liberalization per se is not a sufficient condition for product-quality innovation. In that case high-quality production can be induced by opening up the low quality output sector completely.

Does output sector liberalization per se induce quality innovation? We briefly examine output sector liberalization per se given an input tariff $\hat{t}_{I}$. 


\subsection{OUTPUT SECTOR LIBERALIZATION:}

From lemma2 we know that for all $F_{q} \in\left[0, \hat{F}_{q}\right]$, the domestic monopolist will always invest in quality- innovating $R \& D$ and produce the high-quality good by importing the high-quality input for all tariff rates on low-quality final imports, prohibitive or non-prohibitive. But if $F_{q}>\hat{F}_{q}$ then $(\bar{t}-\hat{t})$ amount of tariff cut is necessary to induce the domestic monopolist to produce the high-quality good. It is also evident from Figure-4, that the critical ad-valorem tariff on low-quality good, $\hat{t}$, varies inversely with $F_{q} \in\left(\hat{F}_{q}, F_{q} *\right)$. In other words

$$
\hat{t}=\hat{t}\left(\mathrm{~F}_{\mathrm{q}}\right), \quad \hat{t}^{\prime}<0 \quad \forall \quad F_{q} \in\left(\hat{F}_{q}, F_{q} *\right) .
$$

\section{FIGURE-4 GOES HERE}

This relationship showing the maximum tariff for a given $F_{q} \in\left(\hat{F}_{q}, F_{q} *\right)$ that is conducive to product-quality innovation, is illustrated in Figure-5 as the QQ segment which is convex and reaches a minimum at $\bar{t}$.

\section{FIGURE-5 GOES HERE}

Consider a set-up cost such as $F_{q}{ }^{0}$. If initially the tariff was $t^{\prime}$ (and correspondingly the economy at pt. A), product-quality innovation does not take place. Removing the tariff barrier on low-quality final imports fully immediately induces the domestic output firm to innovate and switch to the protected domestic market for high-quality good. The above analysis is not surprising. But the important point to note is that given the nature of the domestic input and the complementarity between high-quality input and output, output sector liberalization is anti-protective for the input firm as well, despite a fixed non-prohibitive input-tariff. The output sector liberalization forces the output firm to buy the high-quality input from abroad necessary for 
product-quality innovation. Consequently, the demand for low-quality input dwindles away. Thus

Lemma 3: Full liberalization or critical degree of liberalization, $\bar{t}-\hat{t}\left(F_{q}\right)$, of the output sector causes domestic input firms to shut down regardless of the input-tariff.

Proof: Follows from the complementarity between high-quality input and output.

What is to be recognized is that in face of output sector liberalization, input-tariff becomes redundant. In such a case, i.e. when $t$ is lowered below $\hat{t}\left(F_{q}\right)$, the input tariff should be dispensed with as it no longer fulfills the target with which, perhaps, it was introduced. The net gain that we can expect in such a case is an increase in domestic firm's profit contingent upon low imported input cost and hence an increase in total surplus in the high-quality domestic market and overall welfare thus increases. With this we end our terse discussion on output sector liberalization and next we examine our results in an alternative input protection scheme.

\subsection{RATIO-QUOTA AND QUALITY INNOVATION:}

Consider an alternative input protection regime, where instead of input tariff on imported input there is a ratio-quota in place. In particular suppose the final-good firm while producing the low-quality good is required to purchase k-proportion of his input requirement from the local suppliers and the rest (1-k) proportion is allowed to be purchased from the world market. Note that if the ad-valorem tariff on low-quality final import that is granted is conditional upon meeting this requirement, the regime is essentially the content protection scheme discussed in Corden (1971). Under such content requirement scheme we re-examine how trade liberalization affects the choice of quality innovation. Now, the average and marginal cost of producing the lowquality good under this scheme becomes, 


$$
\mathrm{MC}_{\mathrm{L}}=[k \bar{\gamma}+(1-k) \gamma] c_{I}
$$

To fix ideas, suppose there is a prohibitive tariff on low-quality final imports. Hence,

$$
\pi_{L}(k, \bar{t})=\frac{\left[a-\left\{k \bar{\gamma}+(1-k) \gamma_{-}\right\} c_{I}\right]^{2}}{4}, \quad \frac{\partial \pi_{L}}{\partial k}<0
$$

In general if we do not assume prohibitive tariff on low-quality final imports, profit from selling low-quality good equals,

$$
\pi_{L}(k, t)=\left[t c_{I} \underset{-}{\gamma}-k\left(\bar{\gamma}-\gamma_{-}\right) c_{I}\right]\left[a-(1+t) c_{I} \gamma_{-}\right] \quad \frac{\partial \pi_{L}}{\partial k}<0, \frac{\partial \pi_{L}}{\partial t}>0 \forall t \in[0, \bar{t}]
$$

However, given that the high-quality good cannot be produced by indigenous lowquality input, instead of ratio-quota the government allows all input requirement to be purchased from abroad subject to an ad-valorem tariff $t_{\mathrm{I}}$. As earlier we assume that $t_{I}=t_{I}^{0}=\frac{\bar{\gamma}-\gamma}{\gamma}$. Thus the profit from quality innovation is,

$$
\pi_{H}\left(t_{I}\right)=\frac{\left[a^{\prime}-c_{I} \bar{\gamma}\right]^{2}}{16}-F_{q}
$$

Assume that the value of $\mathrm{F}_{\mathrm{q}}=\mathrm{F}_{\mathrm{q}}{ }^{0}$ (this $\mathrm{F}_{\mathrm{q}}{ }^{0}$ is different from what we had in (16)) is such that, other things remaining the same, for $\mathrm{k}=0$ producing low-quality is profitable and for $\mathrm{k}=1$ producing high-quality is profitable.

From the first assumption we get that

$$
F_{q}>\frac{\left(a^{\prime}-c_{I} \bar{\gamma}\right)^{2}}{16}-\frac{\left(a-c_{I} \gamma\right)_{-}^{2}}{4}=\hat{F}_{q}
$$

and from the second we get that

$$
F_{q}<\frac{\left(a^{\prime}-c_{I} \bar{\gamma}\right)^{2}}{16}-\frac{\left(a-c_{I} \bar{\gamma}\right)^{2}}{4}=\hat{\hat{F}}_{q}
$$


Thus, essentially we consider a value of $\mathrm{F}_{\mathrm{q}}{ }^{0}$ such that $F_{q}{ }^{0} \in\left(\hat{F}_{q}, \hat{F}_{q}\right)$.

Now, suppose initially the value of the parameters are such that,

$$
\pi_{H}\left(t_{I}\right)<\pi_{L}(k, \bar{t})
$$

This corresponds to $\mathrm{k}=\mathrm{k}_{0}$ in figure- 6 .

\section{FIGURE-6 GOES HERE}

Now it is straightforward to check the following effects:

(1) $\mathbf{k}$ is only reduced: Ceteris-paribus if $\mathrm{k}$ is reduced we end-up with no-quality innovation. This is quite intuitive; as $\mathrm{k}$ is reduced the cost of producing the lowquality good falls making it relatively more profitable.

(2) $\mathbf{t}$ is only reduced: If $t$ is reduced, profit from producing the low-quality good falls resulting a downward shift of the $\pi_{L}(k, t)$ curve and thus quality innovation becomes relatively profitable. So in this case output sector liberalization induces product-quality innovation.

(3) t $_{\text {I }}$ only reduced: If only $t_{I}$ is reduced, profit from producing the high-quality good will increase thus making it relatively more profitable. In this case selective input sector liberalization induces product-quality innovation.

(4) Uniform input sector liberalization: Both $\mathbf{k}$ and $\mathbf{t}_{\mathrm{I}}$ reduced: We look at the relative responsiveness of the change in profit from low-quality with respect to change in $\mathrm{k}$ and profit from high-quality with respect to change in $t_{I}$.

$$
\begin{aligned}
& \frac{\partial \pi_{L}}{\partial k}=-\frac{\left[a-\left\{k \bar{\gamma}+(1-k) \gamma_{-}\right\} c_{I}\right] c_{I}(\bar{\gamma}-\gamma)}{2}<0 . \\
& \frac{\partial \pi_{H}}{\partial t_{I}}=-\frac{\left[a^{\prime}-\left(1+t_{I}\right) c_{I} \gamma_{-}\right] c_{I} \gamma_{-}}{2}<0 .
\end{aligned}
$$


It is evident from the above expressions that the relative responsiveness [i.e movement along $\pi_{L}(k, t)$ and the shift of $\left.\pi_{H}\left(t_{I}\right)\right]$ depends on the parametric values and thus the outcome of uniform input sector liberalization is ambiguous. This reinforces the result that input sector liberalization per se might not induce productquality innovation.

\section{CONCLUSION:}

One of the main reasons why majority LDC firms are internationally uncompetitive is that they do not undertake major innovations and thus the products they produce are often of lower quality ${ }^{10}$. Given the foreign buyers increasing sensitiveness towards quality variations rather than cost reductions, export prospects for the developing country firms are becoming limited. The reason often given for this predominance of minor innovations in the developing countries is that the domestic inputs are often of low quality and thus the developing country firms do not have access to high quality intermediates. Given the complementarity between high input quality and high product quality one may think that input sector liberalization might be an instant success in inducing quality innovation and outward orientation by domestic firms. But what we found out was evidently quite interesting and can be summarized as follows:

(a) Input sector liberalization per se may not induce quality innovation. In fact in some situations ceteris paribus input sector liberalization may increase the odds in favour of low quality production.

\footnotetext{
${ }^{10}$ One peculiar aspect of India's technological development is that whatever little innovation has taken place in these countries is minor innovation including adaptation of processes to indigenous raw materials, instead of major innovations at the frontiers of technology (Desai, 1980; Lall, 1984).
} 
(b) Total output sector liberalization, or surprisingly, a suitable degree of output sector protection then is needed to be combined with input sector liberalization so that quality innovation is induced. We also re-examine our above findings in an alternative input protection scenario.

(c) The first policy prescription generates greater social welfare.

(d) We also bring out the endogeneity of the final-good tariff, i.e. the link between extent of protections offered to the final-good and the input producing domestic firms.

Indeed if the high quality input is cost effective at the same time one has to rethink the conventional wisdom of treating input sector liberalization as an instant panacea in inducing quality innovation. Lastly we considered an alternative input protection scheme and arrived at similar conclusions.

One related but important issue that we didn't explicitly consider is the issue of whether a government, given its political constraints, should adopt a 'bigbang' or a 'gradualist' route to trade liberalization. In the context of our paper the policy combination of input sector liberalization coupled with a suitable degree of output sector protection, gives a democratic government an additional route to achieve the desired outcome that too without antagonizing all sections (interest groups) of the society (any domestic industry prefers a protected home market to competition) ${ }^{11}$. Although this policy combination fails to maximize social welfare initially, the government can open up the output sector at a later stage and maximize social welfare. This dynamic perspective coupled with the issue of lobbying and interest groups constitute our future research agenda.

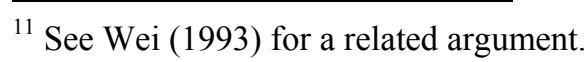




\section{REFERENCES}

Acharyya, R., 1995, “Liberalization, innovation and exports”, Economic and Political Weekly, September 9

Aw and Roberts 1986. Measuring quality changes in quota-constrained Import markets: the case of US footwear, Journal of International Economics, 21: 45-60.

Clemenz, G., 1990, "International R\&D competition and trade policy", Journal of International Economics, 28: 93-113.

Coe, D.T., and E. Helpman (1995), "International R\&D Spillovers", European Economic Review 39: 859-87.

Corden.M. 1971. “The Theory of Protection”, Clarendon Press, Oxford.

Desai, A.V., (1980), "The origin and direction of industrial R\&D in India",

Research Policy, Vol-9, Issue-1 (January), pp.-74 - 96.

Feenstra, R. 1988. "Quality changes under trade restraints in Japanese Autos." Quarterly Journal of Economics, 103, 131-46.

Grossman, G., and E. Helpman (1991), Innovation and Growth in the World Economy, Cambridge, MA. : MIT Press.

Herguera I. and S. Lutz 1998. "Oligopoly and Quality leapfrogging”. The World Economy, 21: 75-94.

Herguera, I., P. Kujal and E. Petrakis (2002). “Tariffs, Quality Reversals and Exit in Vertically Differentiated Industries ". Journal of International Economics 58: 467-92.

Kamien,M.T. and N.L. Schwartz, 1982. "Market structure and Innovation-A survey", Journal of Economic Literature, 13, 1, 1-37 
Keller, W. 1998. “Are international R\&D spillovers trade related? Analyzing spillovers with randomly matched trade partners" European Economic Review 42: $1469-81$.

Keller, W. 2001. "International Technology Diffusion” NBER Working Paper \# 8573.

Lall, S., (1984), 'India's Technological Capacity: Effects of Trade, Industrial and Science and Technology Policies', in M. Fransman and K. King (eds.),

Technological Capability in the Third World, London: Macmillan.

Marjit.S and A. Raychaudhury. 1997 : "India's Exports-An Analytical Study".

Oxford University Press.

Oxfam International 2002, Rigged Rules and Double Standards: Trade, Globalization and the Fight against Poverty, Washington: Oxfam International Advocacy Office.

Porter, M., 1990, The Competitive advantage of Nations (Macmillan).

Premachandra, A. and S. Rajapatirana. 1998. "Economic Liberalization and Industrial Transformation: The Sri Lankan Experience” http// www.econ.worldbank.org, Ref. No. - 681-03C.

Rodrik, D., 1992, “Closing the productivity gap : Does trade liberalization really help ?’. In : G.K. Helleiner, ed., Trade Policy, Industrialisation and Development : New Perspectives (Oxford).

Van Wijnbergen, S. 1992. "Intertemporal Speculation, Shortages and the Political economy of Price Reform.” Economic Journal 102 (415): 1395-1406. Vandenbussche, H. and X. Wauthy. 2001. "Inflicting injury through product quality: How European antidumping policy disadvantages European producers". European Journal of Political Economy, 17: 101-116. 
Wang, Y. 1992. "East European Puzzle and the Chinese Enigma: Institutional Change as a Resource Allocation Problem." Working Paper, University of Minnesota.

Wei, Shang-Jin. 1997. “Gradualism versus Big Bang: Speed and Sustainability of Reforms.” The Canadian Journal of Economics 30, no. (4B) 1234-47.

World Bank. 1991. World Development Report 1991: The Challenge of Development. New York: Oxford University Press.

Young, A. (1991), "Learning-by-doing and the dynamic effects of international trade”, Quarterly Journal of Economics (May 1991): 369-405. 
Table-1

Research and Development Expenditure (\% of Gross National Income)

$\begin{array}{lccccccc} & 1990 & 1991 & 1992 & 1993 & 1994 & 1995 & 1996 \\ \text { Bangladesh } & . . & . . & . . & 0.01 & 0.04 & 0.03 & . . \\ \text { Brazil } & . . & . . & . . & . . & 0.82 & 0.84 & 0.81 \\ \text { Chile } & . . & . . & . . & 0.90 & 0.83 & 0.67 & 0.68 \\ \text { China } & 0.68 & 0.68 & 0.64 & 0.75 & 0.67 & 0.61 & 0.61 \\ \text { Ecuador } & . . & . . & . . & 0.01 & 0.01 & 0.02 & 0.01 \\ \text { India } & 0.80 & 0.75 & 0.73 & 0.77 & 0.73 & . . & . . \\ \text { Korea, Rep. } & 1.88 & 1.95 & 2.10 & 2.32 & 2.60 & 2.71 & 2.82 \\ \text { Malaysia } & . . & . . & 0.40 & 0.35 & 0.24 & . . & . . \\ \text { Mexico } & . . & . . & . . & 0.23 & 0.31 & 0.33 & . . \\ \text { Venezuela, RB } & 0.54 & 0.49 & 0.49 & . . & . . & . . & . . \\ \text { Thailand } & 0.18 & 0.16 & . . & 0.15 & . . & 0.13 & 0.13\end{array}$

Source: World Development Indicators.

2001 CD-ROM, World Bank.

Table-2

High-Technology Exports as Percentage of Manufacturing

$\begin{array}{lcccccccc} & 1991 & 1992 & 1993 & 1994 & 1995 & 1996 & 1997 & 1998 \\ \text { Argentina } & 8.13 & 8.03 & 6.59 & 4.91 & 4.10 & 5.67 & 5.13 & 5.96 \\ \text { China } & . . & 6.51 & 7.20 & 8.33 & 10.47 & 12.44 & 13.14 & 15.54 \\ \text { India } & 4.69 & 4.05 & 4.25 & 4.79 & 5.81 & 6.88 & 6.55 & 5.62 \\ \text { Malaysia } & 38.21 & 38.94 & 41.14 & 44.27 & 46.14 & 44.42 & 49.02 & 54.92 \\ \text { Pakistan } & 0.04 & 0.03 & 0.07 & 0.04 & 0.04 & 0.03 & 0.09 & 0.12 \\ \text { Peru } & . . & 1.63 & 1.68 & 2.59 & 2.55 & 6.01 & 4.65 & 4.09 \\ \text { South Africa } & . . & 4.83 & 4.73 & 4.88 & 5.75 & 5.65 & 7.53 & 8.75 \\ \text { Thailand } & 20.84 & 22.05 & 20.66 & 23.73 & 24.55 & 29.16 & 30.81 & 34.43 \\ \text { Venezuela, RB } & 1.49 & 2.20 & 2.58 & 2.40 & 2.72 & 2.54 & 2.56 & 2.62 \\ \text { Uganda } & . . & . . & . . & 10.99 & 2.11 & 0.25 & . . & 4.59 \\ \text { Bangladesh } & 0.25 & 0.19 & 0.02 & 0.06 & 0.03 & 0.06 & 0.01 & 0.08 \\ \text { Mexico } & 8.60 & 11.26 & 11.61 & 13.93 & 15.18 & 15.82 & 17.57 & 19.26\end{array}$

Source: World Development Indicators.

2001 CD-ROM, World Bank. 